\title{
International Cooperation, Community-Based Tourism and Capacity Building: Results from a Mpondoland Village in South Africa
}

\author{
Dr. Andrea Giampiccoli \\ Ecotourism Department (Pietermaritzburg Campus), Durban University of Technology, \\ P. O. Box 1334, Durban, 4000, South Africa. \\ Email: andrea.giampiccoli@gmail.com \\ Mr. Sean Jugmohan \\ Ecotourism Department (Pietermaritzburg Campus), Durban University of Technology, \\ P. O. Box 1334, Durban, 4000, South Africa. \\ Email: seanj@dut.ac.za \\ Oliver Mtapuri \\ University of Limpopo, P.O. Box 756, Fauna Park, Polokwane, 0787, South Africa. \\ Email: simbaomtapuri@yahoo.com
}

Doi:10.5901/mjss.2014.v5n23p657

\begin{abstract}
Capacity building has enjoyed little attention in the tourism literature. This paper attempts to fill this gap with a proposition that capacity building for CBT development should be steeped in the local cultural context and go beyond tourism matters. This paper is a result of literature review, observation and ethnographic experiences in the study area. The paper argues that while tourism specific capacity building and skills are a pre-requisite, the ultimate aim should go beyond 'technical' skills to empower individuals as well as the community for holistic community development and well-being. With capacity building, communities are able to embrace community harmony and cohesion and resist co-option for individual gain.
\end{abstract}

Keywords: Community-based tourism, capacity building, Mpondoland, international cooperation, community development.

\section{Introduction}

The concept of community-based tourism (CBT) as an alternative form of tourism has been around since the 1970s (Mitchell and Muckosy 2008:1; Telfer 2009:56; Zapata et al. 2011:726). Judgments on the actual result of CBT projects or ventures have been mixed. Some authors remain critics and doubtful such as Goodwin and Santilli (2009); Mitchell and Muckosy (2008) Blackstock (2005:41); while others are more inclined to give a chance to CBT and are generally favorable towards possible positive CBT outcomes, like Moscardo (2008:173), Ndlovu and Rogerson (2004:447), Nyaupane, Morais and Dowler (2006:1374). Blackstock $(2005: 40,41)$ writes that CBT is guided by neo-liberal strategy instead of promoting empowerment and social justice and "CBT literature is focused on sustaining the tourism industry, unlike community development's commitment to social justice and empowerment" (on the relation between CBT and neoliberalism see also Zapata et al., 2011; Manyara and Jones, 2007; Giampiccoli and Mtapuri, 2012).

While the market for CBT is expected to grow (see for example CBI, 2011) one needs to simultaneously consider human capacity for the growing CBT sector within each destination. A good assessment and understanding of local human resources is essential for a CBT venture to decide if a community will be able to sustain and meaningfully be involved in sustainable tourism development (Asker et al. 2010:50). While community capacity building (CCB) is important, it has received only limited attention in the tourism literature (Aref et al. 2009:400) with some examples however being present (Aref and Redzuan 2009a, 2009b; Aref et al. 2009; Aref, Gill, and Aref 2010; Manyara and Jones 2007; Moscardo 2008).

The link between local culture and development where local culture is seen as a point of departure and a key issue in community development has been proposed by various authors (Anacleti 1993:45; Ife 2002:183). Giampiccoli and Hayward Kalis (2012) specifically show the link between CBT development and local culture and how local culture, as 
much as not determinant, can be a scaffold to support the development of CBT.

This paper put forward theoretical argument on the need of capacity building in CBT as a form of holistic community development by examining issues of capacity building in relation to an international cooperation project (as a historical context). The paper briefly point out (to corroborate the theoretical argument) a case study from Mpondoalnd, South Africa where the outcome of an internationally supported project has filtered to a locally 'controlled' CBT venture (a tent campsite) not related to the international cooperation project itself and have also influenced the general relationships amongst community members. The term 'lucky coincidence' is used in the title to reflect how a community got involved by in an international CBT project and being able to 'control' a locally established campsite initially developed by the South African Government.

The paper argues that capacity building in CBT should be seen to go beyond specific 'technical' tourism skills to more general empowerment at community and individual level and be useful beyond the specific CBT project. In addition it argues that capacity building should be built with respect in the context of local culture for it to be understood by the community as a development tool. The research recognizes the possible negative effects of a lack of inadequate capacity building on community development processes in cases where external money and external management procedures are introduced.

\section{Literature Review}

There is a variety of interpretations and understandings of CBT concepts and practices in the literature (Flacke-Neudorfer 2008:246; Ndlovu and Rogerson 2003:125). Notably the lack of capacity building has been acknowledged as a barrier to promote community development through tourism, especially in Third World countries (Aref, et al. 2009; Moscardo 2008). In South Africa capacity building and tourism skills are central requirements to improve the tourism industry (DoT 2011:40; Kaplan 2004:217). CCB plays a central role in tourism development (Aref and Redzuan 2009a:22) and it is a critical aspect in community-based enterprises (CBEs) in tourism (Manyara and Jones 2007:639).

Capacity building can take many forms such as strengthening human resources, organisational and individual capacity, developing appropriate facilities and training in tourism and assessing tourism impacts (Aref 2011:348). Furthermore, and importantly CCB should be understood at different levels (individual level, community level and organizational level) and in various dimensions (Aref et al. 2010:173). Capacity building can be traced back to the 'conscientização work of Paulo Freire' and '[i]t is surely about enabling those on the margins to represent and defend their interests more effectively, not only within their own immediate contexts but also globally' (Eade 2007:632, 637). CCB 'is about community empowerment' (Aref and Redzuan 2009a:24) which runs across social, political and economic boundaries (Laverack and Thangphet 2007:183). Thus, capacity building should be viewed within a holistic empowerment framework and tourism should be the specific sector, the 'excuse', within which this empowerment can take place. Weiler and Ham (2002:53) suggest that CCB training should include the preparation of local trainers with the aim of building long-term local capacity and moving away from dependency on the outside.

There is a close relationship between community development and local culture. Ife (2002:183; see Anacleti, 1993:45 for an African context) clearly states that community development should happen within the local cultural context. The relationship between CBT and local culture is vitally important (Giampiccoli and Hayward Kalis 2012) and Timothy (2002:15) argues that "Community tourism [...] is not detrital to their [community members] culture, traditions or indeed, their day-to-day convenience". Local traditions and ways of life should not be jeopardised by the development of CBT. Culture should be the main anchor and asset for CBT development. As such, facilitators (the 'experts'), who are often necessary (Giampiccoli and Mtapuri, 2012:35) should value local indigenous knowledge, culture, resources, skills and processes (Chambers 1983; Ife 2002; see also Giampiccoli and Mtapuri, 2012:35 and Mtapuri and Giampiccoli, 2013 about the characteristics of ideal facilitation approaches in CBT).

Local culture is not static but evolves independently as it interacts with the other external cultural milieu to become a transformative force (Escobar 1995:226). In this context, community-based enterprises (CBEs) can also improve their local cultural management approaches through infusion of external management features (Peredo and Chrisman 2006:321). Briedenhann and Wickens (2004:198) have argued that, despite historically not congruous to local culture, charging for hospitality is now adopted in rural African communities as a way to generate income. In relation to Mpondoland, Hunter (1979:373) observes, that the traditional tendency was not to pay for food but changed when migrant mine workers increasingly travelled to and from the urban centres, with the result that the "sale of food to travellers is beginning to be usual." Thus cultural adaptation happens in relation to tourism and hospitality as well.

In Mpondoland people are /were much attached and are followers of the principle of Ubuntu (Hammond-Tooke in Mcetywa 1998:8). The concept of Ubuntu links the individual to the community and advocates co-operation between 
individuals while maintaining the freedom of the single (Bhengu 2006:58, 125). In the case of Mpondoland, people embrace indigenous knowledge as an important ingredient in the promotion of their own livelihoods (Simukonda and Kraai 2009:54). Giampiccoli and Hayward Kalis (2012:183) have argued that local culture is important and necessary but not a sufficient condition for sustaining the development of CBT. Other elements are crucial. In the Indian state of Kerala where there is a local communist cultural context the cooperative Kudumbashree scheme follows strict rules with respect to how profits from its tourism venture are shared in order to avoid disputes (Baker 2008:207).

However, most development projects follow standardised western neoliberal approaches where local realities are ignored, or are seen as inferior and not useful, or overlooked, disregarded, misunderstood and considered inappropriate such that many poverty alleviation programs have "degenerated into global 'charity,' rather than serving to build local and durable self-reliance" (Peredo and Chrisman 2006:311; see also Bianchi 2002:273).

Capacity building has received only limited attention in the tourism literature (Aref et al. 2009:400). There are few studies available on the long-term effects of inadequate capacity building in CBT development projects. As such the paper argues that CBT development can also serve as a community training platform that could be useful in general community development context. This issue is supported by Mitchell and Ashely (2010:23) who argue that that participation in tourism allows people to learn skills which can be applied in different ways to boost their livelihoods.

Capacity building in the context of CBT is viewed as having certain unique characteristics compared to other forms of tourism because it has the potential to empower communities to run tourism businesses, to learn through tourism education and training, business advisory support which enhance business confidence, community cooperation and individual self-esteem (SNV 2007:14). Other authors like Hainsworth (2009:113) support the same view by arguing that it is a forum for community-based decision making associated with all community matters. Ross and Wall (1999:129) argue that development of tourism should be done in tandem with other interventions meant to bring positive change in communities within a broader plan of resource utilisation. While guides are considered to be contributors to sustainable tourism in the Amazon, they are also seen as valuable at various communities' levels and spheres given their many social roles and therefore need proper training/education (Pereira and Reidar, 2012:89). Thus, as mentioned in a CBT handbook CBT can be the pivot upon which to build more general community capacities, as written the capacities learned in CBT can be utilized "by the local community in venturing into the other (and often more stable) sectors of the rural economy" (Hamzah and Khalifah, 2009:14).

Capacity building should be seen as a necessary pre-condition in the implementation of practical projects. This is supported by Suansri (2003:12) who views it as an imperative to capacitate host communities "[b]efore developing CBT..." This should be done within a medium-long-term approach not in a 'quick fix' strategy (Victurine, 2000:228; see also Asker, Boronyak, Carrard and Paddon, 2010:11).

Aref and Redzuan (2009b:210) identified community leadership as a key factor in developing tourism in local communities. Malatji and Mtapuri (2012:9) also specifically support capacity building of management committees and tribal authorities on matters related to team work in order to put a stop to unnecessary squabbles and desire to selfenrichment. Admittedly, the role of a leader is not homogeneous, and can have a positive or negative influence (Honggang, Sofield, and Jigang 2009:1; Scheyvens 1999:68). It has been noted that problems can include internal community conflict arising from the flow of benefits from new commercial ventures or other use of wild resources in the "tension between traditional and democratic forms of community governance" (Koch 2004:80). An important issue (also highlighted in the present case study) is that external private entities partnership with communities is usually through lease pay-out agreements. These payments ${ }^{1}$ can have two effects: first they can either increase or maintain dependency on the 'free cash'; secondly, if not properly managed, they can cause greater conflict within the community over their control and more powerful actors could hijack most revenues. As noted by Scheyvens and Russell (2012:429) in a case in which Fiji landowners became solely dependent on lease pay-outs and thus neglecting other opportunities to earn a living or pooling monies for further projects such as upgrading infrastructure. Additionally cases existed in which chiefs were also involved in similar arrangements.

New events that happen within a common cultural setting can generate new problems. Literature suggests that communal resources management has been jeopardised as a result of internal conflict (Boggs, 2004:157). As generally expressed in the literature on common property a Botswana case study propose that in Community-based Natural Resources Management (CBNRM) communal approach has been disturbed by the community involvement and consequential benefits in CBNRM projects (Boggs, 2004:157). In relation to cultural evolution and CBNRM, Boggs

1 The companies disbursing the payment are not necessarily (and usually are not) aware of the use of the money once payment to the community is done and therefore the companies cannot be (usually) held responsible (or connected) for any misuse of the concession fees. 
(2004:157) suggests that "cultures are dynamic and fluctuating. In order to succeed, the CBNRM model must incorporate mechanisms for change that allows it to adapt to changing environments."

While different interpretations and difficulties of the concepts of 'community' are acknowledged Giampiccoli and Hayward Kalis (2012:176) see community as consisting of individual members being economically and socially interwoven via a specific cultural background within a geographic boundary. This also applies to Mpondoland with its own geographical boundaries, economic and social relations, natural resources and assets which are part of Mpondo culture (Giampiccoli and Hayward Kalis, 2012:176). Given that community development should start from the specific local culture and knowledge base, thus the needs of communities differ such that the capacity-building needs will necessarily have to be community-specific (Manyara and Jones 2007:407).

\section{Methodology}

This paper makes use of secondary sources, fieldwork observations, personal communication and attendance in meetings related to the campsite management and ownership in Mpondoland, South Africa. A field visit was done by the authors where relevant issues where observed and questioned. One of the authors is very familiar with Mpondoland and has over the last 9 years regularly spent time (weeks at times) in the village under study attending various community meetings and always following community developments and the happenings in the campsite. This gives this work some ethnographic finesse.

\subsection{Case study context and background}

The Mpondoland coast ${ }^{2}$ was chosen as one of the government supported Spatial Development Initiatives (SDIs). The Wild Coast SDI ('the international cooperation project' or 'the project') specifically focused on tourism with the support of the European Union (EU). The focus of the international cooperation project on CBT was based on the replication of a previous successful model of CBT development, the Amadiba Adventure project. The Amadiba Adventure project was developed by a local NGO with the local community and funded by a national agency (Ntshona and Lahiff 2003:2, 27, 40; MTR $^{3}$ 2003:172; Russell and Kuiper 2003:159). From adopting a CBT approach, the international project eventually shifted towards a more private business approach (Giampiccoli 2010; Ntshona and Lahiff 2003). Initially, the camps/lodges were meant to be fully controlled by the communities involved. Eventually, the projects of camps/lodges shifted focus towards partnership agreements between the communities and external private entities while the more community oriented village-based accommodation was left out completely to die (Giampiccoli 2010; see also Wright, 2005:61).

One of the villages involved in the project also boasts a campsite as an accommodation option. The campsite has been historically under control of the adjacent Nature Reserve. However, currently there is confusion on who controls the tourism business in the campsite (Personal observation). In this de facto vacuum, over the years, the community has 'taken over' the 'management' of the campsite and is actually collecting revenue from tourists who use the campsite despite the absence of any formal agreement with government (Personal observation; personal communication 2012). The argument in this paper is not whether the campsite has been managed 'legally' or not by the community but to understand whether or not the campsite has been properly managed and what influences this is having on community cohesion. The proper working of the campsite is important for "the benefit of the struggling, poor, unemployed community" (Personal communication 2012).

\section{Results}

\subsection{Capacity building}

The EU supported project has been implemented in a top-down manner and guided by international consultants (MTR 2003:31; Wright 2005:36; see also Kepe, Ntsebeza and Pithers, 2001:1 on various problem related to the Wild Coast $\mathrm{SDI})$.

Two different problems related to capacity are here observed. Firstly, there is lack of capacity in the implementing agency (the project implementer/facilitator) in relation to CBT development. Secondly, there is lack of capacity at

\footnotetext{
2 The Mpondoland coast is part (a section of) the Wild Coast.

${ }^{3}$ Mid Term Review.
} 
community level. In relation to the implementing agency(ies) involved in the project the MTR $(2003: 140,17)$ argues that the project has achieved what it could within its capabilities and that capacity constraints were identified at government level and possible remedial action were proposed. The project contractual framework advance the need to build capacity of government "to plan, manage and implement responsible/sustainable tourism"4" (MTR 2003:52). It seems logical that without proper capacity in the implementing side the project suffers deficiencies. To note that Municipalities in the Wild Coast region are without enough capacity in this regard (Development Management Services, 2005:104)

The second issue and more relevant here is related to the low capacity of the beneficiaries, the community. The MTR $(2003: 57,74)$ notes that there is low capacity due to low educational levels of community members in the Wild Coast area. Working in very poor, rural and marginalised communities lacking a strong educational/skill base should, obviously, have been identified and recognised as a central issue to be resolved from the start of the project. As noted by one of the employees, the 'top down' approach by the EU in terms of Programme conceptualisation, design and implementation, lacked a significant participative ideology (Wright 2005:107, 111). With specific reference to the management and objectives of capacity building within the EU funded project, the same author ${ }^{5}$ (Wright 2005:112) notes that "[c]apacity-building is viewed in the programme design as one component of achieving the predetermined objectives, rather than the programme itself being viewed as a capacity-building process."

Regarding capacity building, Wright $(2005: 122,84,86)$ explains that institutional capacity is important for the success of the programme and as such training interventions should be "an integral part of the programme's purpose and objectives" and the process of capacity-building needs should be based on proper community needs evaluated through a participatory approach (fact that did not happen in the project). There were no guiding principles regarding capacity building and there was general reclutance to adopt a lomg-term approach which proper capacity building entails (Wright, $2005: 16,61,63)$. This issue has been noted by the MTR (2003:14) that imparting business development skills was found wanting and generally inadequate. To note that, interestingly and very importantly in relation to community business projects, the problem was the lack of skills not the insufficiency of market, the time was too short for proper capacity development and that consequently compromised the sustainability of the project, thus: "[s]ustainability of some community based ventures questionable, in terms of the business skills capacity of the staff but not in terms of market. It was known from the start that four years was too short a period to develop these skills, but there was no focus on establishing a business support system at the outset, to ensure sustainability once the Programme ended" (MTR, 2003:67). Thus if proper skills were supplied more positive outcomes could have been achieved. The NGO in charge of the training was not an accredited institution and lacked the required skills to address the identified skills needs (MTR 2003:62). These issues suggest that capacity building and skills development within the project were inappropriate, inadequate and not properly organised and delivered. It has been noted that "[t]he provision of training has been problematic" and the Training of the Trustees had not received appropriate attention therefore not fully addressing the log-term sustainability of the community-based ventures (MTR $(2003: 26,126,141)$. Thus, training supposed to be a preelement of the project itself when capacity is lacking, as such it has been advanced that the "programme was started prematurely and that the focus of activities in the first phase should have been on establishing an enabling operating environment and embedding the programme locally, before embarking on specific projects" (Robinson \& Massyn in Development Management Services, 2005:29).

Capacity building and tourism skills are central to the development of the tourism sector in South Africa (DoT 2011:40; Kaplan 2004:217). In this respect, the EU supported project, although only related to this specific project, did not have profound impact in relation to the issues of capacity building and skills.

\section{Discussion}

The village in this study, as do other communities involved in the international cooperation project, benefits from a monthly payment (the concession fee) from the private companies who are signatories to the partnership (concession

\footnotetext{
4 "It might be unreasonable to expect the PMU [Project Management Unit] to build capacity in an arrangement where there are questions regarding commitment and will, where government personnel are changing so fast and where their initial primary points of contact in $D E A T$ were in effect consultants to the department. This component really required the secondment of the relevant officials to the programme. The result is that the PMU has tended to step back from playing a lead role in this, however it is questionable, had they been more assertive and ambitious, whether they would have been received with much enthusiasm from a somewhat ambiguous counterpart(s)" (MTR 2003:52).

${ }^{5} \mathrm{Mr}$. Wright reported that he "was employed in April 2003 by PondoCROP (EU Programme implementing agent) as a business development manager in development node 3" (Wright 2005:7).
} 
contract) agreement 6 . The fee payment, which is discussed in this paper, can be interpreted as a form of 'free cash' payment to the communities, created tensions and the upsetting of an internal historical balance and understandings. This does not mean internal problems were non-existent previously. This situation has affected and exacerbated the working relationship within the community in its development process and jeopardised the local campsite management (which was not part and does not have any type of connection with the EU supported project had it not been located within the same village).

The concession fee can be viewed as a very valuable amount of money in the context of a poverty stricken community. However, these funds, without proper capacity which empowers community members in tourism and general development matters, risks to negatively impact the relationship amongst community members who are historically embedded in their cultural context. The problems surrounding the revenues from the concession fee have escalated in the village to overflow to matters related to the campsite and also affected inter-relationships among members. It can be surmised that the absence of capacity building processes during the implementation of this international cooperation project has been a contributing factor to causing many problems in the villages. In summary the three problems below have worked together to 'destabilise' the village:

- Absence and/or inadequacy of capacity building during the international cooperation project;

- Shift in approach during implementation of the international cooperation project from a more authentic CBT model to community-private sector partnership model;

- Confusion surrounding who owns and manages the tourism business in the campsite ${ }^{7}$

The international CBT cooperation project's approach was problematic as it did not help either to promote improvement in CBT specific skills or other more general community development issues. The project did not take in adequate consideration as instead should (in proper timeframe) local cultural matters such as gender relationship (MTR, 2003:128). MTR (2003:166) suggests that amongst the problems to be resolved are "gender issues, environmental aspects, poverty reduction, institutional and socio-cultural factors."

The formation of the village level Community Trust has, theoretically, brought more balanced representation as "Trustees are drawn from both male and female members and all are involved in decision making processes" (MTR, 2003:129). In the village under study both females and males are represented in the Community Trust. However, the Trust did not originate from within the community meeting but it has been externally introduced. Although a community meeting was convened to select the Trustee, it was not the community meeting that independently decided to establish the Community Trust. If happened, this community internal decision will have enhanced the sense of ownership and facilitated an autonomous learning about Trust. External entities will intervene in the same time in adequate capacity building following the community independent decision. Instead, the newly established Community Trust is an external introduction. As much as the newly formed Community Trusts is an 'independent' entity its working is still within the framework of traditional power relation. Importantly the Community Trust is now controlling the new resources (concession fee) thus favouring a greater exploitation of traditional community internal power relationship in conjunction with the new (Community Trust) structure of power now at work. The inadequate capacity building of the Trustee make easier to voluntary (or not) mis-manage the Trust. Instead as already mention new management system of communal resources "should incorporate mechanisms for change that allow ... [the culture] to adapt to changing environments" (Boggs, 2004:157) where the local culture is appreciated in its diversity and, importantly, is seen "not as static but as a transformed and transformative force" (Escobar, 1995: 226).

As much as the historical control of communal resources was also within specific form of structural power unbalance it was made in a way to guarantee to everyone 'a slice of the cake'. For example, although the use of land (which is considered a key communal resource) was not managed in an equal manner "there is no evidence to suggest that commoners could be excluded from land" (Beinart, 1982:18). Thus, communal land tenure was maintained through an unbalanced mutual 'agreement' within specific decision-making process associated to the local cultural context where "for the bulk of the population, communal tenure was their ultimate guarantee to access to both arable plots and grazing [...] the allocation of land through chiefs and headmen, rather than by the state, enabled the mass of the people to exercise some control over land through the political process surrounding local decision-making" (Beinart, 1982: 126).

The new arrive of 'free cash' (see here as a communal resource as it is suppose to be for the benefits of the whole community) have instead divided the community and individualised, instead to remain communalised, the hunt of control

\footnotetext{
${ }^{6}$ The external company(ies) involved cannot be seen as the promoter of the shift of the project approach from purely CBT to 'partnership' or any problem derived from the concession fees at community level.

${ }^{7}$ The government built a new office and a new abolition facility in the campsite leaving, however, confusion is present about the 'ownership' and management issues of the campsite tourism business. 
of the new monetary resource. Previously, the community was able through its historical progression, to keep problems within specific limits and maintain a general community (although not necessarily balanced) wide approach to development. Foreign funders, without using the local cultural context as a pivot on which to build on and without proper adaptation to local systems and proper capacity building in the required fields (such as simple money management), have created divisions within the community by reinforcing traditional, or introducing new (the community Trust), structure of power. The revenue being generated could be used for the benefit of the entire community instead of enhancing internal conflict. The new resource is directing community members on a more individualised approach instead of communal one. This does not mean that the community is not able to manage the new revenues but that the new income, as it has been 'parachuted' in the community, can exacerbate internal conflict and different views on how the money generated should be used.

The campsite coincidently fell within the management of the community, although informally outside any legal agreement with other relevant bodies. This 'taking over' of the campsite by the community happens to be at an opportune moment as it happened just after the end of the EU funded project and approximately at the start of the concession fee. As written above capacity building was not properly carried out in the project. The campsite could have been improved and managed autonomously by the community with the funds collected in the form of levy (the concession fee). The subsequent independent development of the campsite as a community owned and managed venture (that is a CBT venture) has been dysfunctional and problematic. Previous campsite and community meetings were usually well attended by a large number of people, however these meeting are now usually deserted (if done at all) as community members feel that their voice and practical actions are not heeded. With no possibilities of their inputs being considered, community members have lost the desire to manage the campsite leading to the prevailing situation of virtually no management other than 'survival' management on a day-to-day basis without any plan. This ad hoc management style has led to various problems such as lack (mismanagement) of water in the campsite ablution facilities. Operational management matters are challenging, such as removal of refuse, security, animals trespassing, cleaning and purchasing of essentials required to run the campsite. With high level of mistrust and inadequate management capacity, it is not easy to move the campsite forward. The campsite is susceptible to decline as the structures deteriorate which will be another impediment for further development. The campsite is situated in a very tourist marketable location and proper management and marketing could very much increase the campsite earning. In such a situation, it is necessary for external actor(s), such as government, to intervene and mediate to help to resolve the internal problems (see also Boggs 2004:157). ${ }^{8}$ As similarly proposed for the Wild Coast project:

Local capacity needs to be developed to take over and fund ongoing operations; to enhance community awareness, skills and know how; and to raise community trustees to a level where they will be competent to manage community-based enterprises. The mere presence of private-sector operators is not a guarantee of sustainability; the businesses must also be profitable" (Wright, 2005:99).

At the same time showing the direction of intervention in the original Amadiba project, which was nationally and internationally recognised as a model to follow (Ntshona and Lahiff 2003:40) show the negative and positive aspects of external involvement shift understanding of business management from a community to a one based of private business. Thus:

It is important to note that the recent restructuring of the trail has come about not as a response to the concerns of those most directly involved in its day-to-day operation, or to the demands of its clients, but under the influence of external developments, in the form of very substantial EU funding [...] While the supply of additional funds and expertise can certainly assist the Amadiba trail in meetings its objectives, including provision of benefits for poor members of the community, it has also put pressure on the trail to conform to certain standards, drawn largely from the world of private business [...] (Ntshona and Lahiff 2003:41).

The original model, the Amadiba project, was meant to empower previously disadvantaged communities by ensuring their participation in tourism ventures through sole ownership of enterprises such as horse and hiking trails

\footnotetext{
${ }^{8}$ Importantly, up to the time of writing the way the revenue from the concession fee and campsite operations are used need to be verified through awaiting community internal financial reports and bank statements which they have been requested by community members but, however, consistently not presented or not fully disclosed in all their facets. This stalled situation continues to keep mistrust and unworkable relationship amongst most community members. When requested reports and documents will be available and full clarity will be done a rebalancing and workable relationship amongst community members could (or not) maybe be re-established. While it lately seems to be possible moves towards reconciliation much remains to be done in relation to the practical control and use of the finance accrued from the levy payment and campsite operations.
} 
(MTR 2003:138). However this model shifted towards a neo-liberal partnership framework (Giampiccoli 2010). Also the Replication Study, to which the programme manager agree, "advocates moving the emphasis from community owned and managed tourism ventures competing in the privates sector, to private-sector operating in the community area, with strong linkages to increase the spread of benefits" (Wright, 2005:61). Time constraint was also a problem favouring private sector involvement, thus "The PMU, with limited resources and within the remaining programme timeframe, is aiming to maximise the return to the community through a strategy orientated around private-sector linkages for supporting community business in long-term sustainability" (Wright, 2005:66).

Long term effect of the lack or inadequate capacity building in the project has been advanced already in 2005. Thus, During implementation, the concept of nature-based tourism was introduced to selected communities over 280 kilometres of coastline. For the large majority of these communities, nature-based tourism was a foreign concept embedded in the 'not knowing' and thereby highlighting capacity weaknesses. As a result, the communities lacked capacity to meaningfully contribute to the implementation process. It can be argued that this approach undermines beneficiary peoples, impacts on self-esteem and can leave people more vulnerable than before (Wright, 2005: 102).

The limited capacity building provided to the community did not meet the necessary long term- sustainability of the project thus to resolve "the programme management has turned to the private tourism sector to support the lack of community business capacity" (Wright, 2005:103).

The example presented here is not unique (see for example Peredo and Chrisman 2006:311; Boggs, 2004:157). This indicates the role which external facilitators can play either for the good or the detriment of the project. At community level, the unequal distribution of benefits contradicts the philosophy of CBT Suryia (2010:3). Ideally, CBT should work towards more equal power relations whatever within the community of with external entities (Giampiccoli and Hayward Kalis, 2012:176). These authors (Giampiccoli and Hayward Kalis, 2012) note that specific forms of evolution and management of community-based development depend on specific contexts that are based on particular cultural heritage and historical forms of relationship within the community where elites can either enhance or destroy social cohesion in dispensing their functions in community development. This particular point is also relevant to this case study and is also supported by Manyara and Jones (2007:642) who argue that "[i]f CBE initiatives were able to emphasise independence, address local community priorities, enhance community empowerment and transparency, discourage elitism, promote effective community leadership and develop community capacity to operate their own enterprises efficiently, then the impacts of CBEs on economic development and poverty reduction would be greatly enhanced." As much as specific community contexts vary, the influence of capacity building on wider community development should be seen as a central matter in empowering communities and individuals including against possible co-option and control of resources by specific individual or elite groups for their private gains within or external to the community.

\section{Conclusion}

The present case study maintains that capacity building in CBT should have dual aims that are connected: first to adequately supply skills that lead to the ownership, management and control of the CBT itself; secondly, such capacity building should be planned and implemented in a way that should be useful beyond CBT by adding value in other community development matters at both individual and at community level. The international development supported project on CBT discussed here showed that capacity building was insufficient or not properly done to address both specific tourism skills and other general community development matters. The shift in direction from the CBT approach coupled with inadequate capacity building had escalated community problems and internal conflicts.

Better implementation of concepts and practices of capacity building in CBT development projects is necessary to properly facilitate the process by which poor communities can own, manage and control their local tourism initiaves in a sustainable self-realiant way. In addition capacity building in CBT should incorporate a broader approach where the concept of capacity building goes beyond strict technical tourism skills to embrace more general community development matters.

Communities are often judged as the guilty party when development projects do not work. The Community must certainly take ownership, responsibility and accountability in a project and cannot hide behind other actors' inadequate work or remain passive in a 'begging/dependency' approach. However, they are usually become the only guilty party while external structures are exonerated from their own possible intentional or unintentional wrongdoing and incapacity. The failure of a project and the blame on the local communities is institutionalized through the interpretation that communities are not responsible, innapreciative and not dedicated enough to achive success (de Beer and Marais 2005:55; Pleumaron 2002). These notions should be abandoned.

Although Peredo and Chrisman (2006:311) see possible positive change in project approaches, they argue that 
"the real effect of many developmental activities has been to compromise community support systems and to contribute to the creation of real poverty." Similar issues remain valid in CBT projects where western notions of tourism development remain predominant especially in traditional methods of CBT planning (Sammy 2008:76).

Often, external facilitators do not take into account the long-term effects on communities of their actions in development projects once the project has come to an end. Proper capacity building needs to be done to decrease the chances of generating improper outcomes and to empower communities and individuals to resist possible internal or external individualised exploitation of, and advantages from, community resources.

\section{References}

Anacleti, O., 1993, 'Research into Local Culture: Implications for Participatory Development', Development in Practice, 3(1), 44-47.

Aref, F. and Redzuan, M., 2009a, 'Community Capacity Building for Tourism Development', Journal of Human Ecology, 27(1), 21-25.

Aref, F. and Redzuan, M., 2009b, 'Community Leaders' Perceptions toward Tourism Impacts and Level of Community Capacity Building in Tourism Development', Journal of Sustainable Development, 2(3), 208-213.

Aref, F., Gill, S., and Aref, F., 2010, 'Tourism Development in Local Communities: As a Community Development Approach', Journal of American Science, 6(2), 155-160.

Aref, F., Ma'rof, R., Zahid, E., and Sarjit, S. G., 2009, 'Barriers of Tourism Industry through Community Capacity Building', International Review of Business Research Papers, 5(4), 399-408.

Aref, F., 2011, 'Barriers to community capacity building for tourism development in communities in Shiraz, Iran', Journal of Sustainable Tourism, 19(3), 347-359.

Asker, S., Boronyak, L., Carrard, N. and Paddon, M., 2010, 'Effective community based tourism: a best practice manual', APEC Tourism Working Group. Griffth University: Sustainable Tourism Cooperative Research Centre.

Baker K., 2008 'Kerala's Strategy for Tourism Growth: a Southern Approach to Development and Poverty Alleviation', in P. Burns and M. Novelli (eds.), Tourism Development: Growths, Myths, and Inequalities, pp.192-216, CAB International, Wallingford.

Beinart, W. 1982 The political economy of Pondoland 1860-1930. Cambridge University Press, Cambridge.

Bhengu, M. J., 2006, Ubuntu: the global philosophy for humankind, Lotsha Publications, Cape Town.

Bianchi R. V., 2002, 'Toward a New political Economy of Global Tourism', in R. Sharpley and D. J. Telfer (Eds.), Tourism and Development Concepts and Issues, pp. 265-299, Channel View Publications, Clevedon.

Blackstock, K., 2005, 'A critical look at community based tourism', Community Development Journal, 40(1):39-49.

Boggs, L., 2004, 'Community-based natural resource management in the Okavango Delta', in C. Fabricius (Ed.), Rights, resources and rural development. Community-based natural resource management in Southern Africa, pp.147-159, Earthscan, London.

Briedenhann, J. and Wickens, E., 2003, 'Rural Tourism - Meeting the Challenges of the New South Africa', International Journal of Tourism Research, 6: 189-203.

CBI, (2011). Promising EU export markets for CBT. Ministry of Foreign Affairs of the Netherlands CBI - Centre for the Promotion of Imports from developing countries, viewed from http://www.cbi.eu/marketintel/Community\%20Based\%20Tourism\%20(CBT):\%20 promising\%20EU\%20export\%20markets/165824

Chambers, R. 1983 Rural Development: Putting the Last First, Longman, Harlow.

de Beer, F. and Marais, M., 2005 'Rural communities, the natural environment and development -some challenges, some successes', Community Development Journal, 40(1), 50-61.

Development management services, 2005. Spatial development framework for the Wild Coast. Development Management Services, Mayville.

DoT - Department of Tourism, 2011. National Tourism Sector Strategy, Department of Tourism, Pretoria.

Eade, D., 2007 'Capacity building: who builds whose capacities?', Development in Practice, 17(4-5), 630-639.

Escobar, A., 1995, Encountering Development: The making and unmaking of the Third World, Princeton University Press, Princeton.

Flacke-Neudorfer, C., 2008, 'Actors or victims? Actor oriented perspectives on new form of tourism', in P. Burns and M. Novelli (Eds.), Tourism Development: Growths, Myths, and Inequalities, pp. 239-258, CAB International, Wallingford.

Giampiccoli, A. and Hayward Kalis, J., 2012, 'Community-based tourism and local culture: the case of the amaMpondo', Pasos. Revista de Tourism y Patrimonio Cultural, 10(1), 173-188.

Giampiccoli, A, and Mtapuri, O., 2012. 'Community-Based Tourism: An Exploration of the Concept(s) from a Political Perspective', Tourism Review International, 16(1):29-43.

Giampiccoli, A., 2010, Globalisation, development and community-based tourism in developing countries: a case study of Pondoland, Eastern Cape, PhD thesis, Geography Department, University of KwaZulu-Natal, Durban.

Goodwin, H. and Santilli, R., 2009 'Community-based tourism: a success?', International Centre for Responsible Tourism, Occasional Paper No. 11.

Hainsworth, D., 2009, 'Community Tourism and Broad-based Local Development: The Case of Doi Village, Thua Then province, Vietnam', in B.A.O. Jigang (ed.), Tourism and community development. Asian Practices, pp. 121-134, World Tourism Organization, Madrid.

Hamzah A. and Khalifah Z, 2009. Handbook on Community Based Tourism "How to Develop and Sustain CBT". Asia-Pacific Economic Cooperation Secretariat. Singapore. 
Honggang, X. U., Sofield, T. and Jigang, B. A. O., 2009 'Community tourism in Asia: an introduction', in B.A.O. Jigang (Ed.), Tourism and community development. Asian Practices, pp. 1-17. World Tourism Organization, Madrid.

Hunter. M., 1979, Reaction to conquest. Effects of contact with Europeans of the Pondo of South Africa, David Philip, Cape Town. Ife, J., 2002, Community Development: Community-based alternative in the age of Globalisation, Pearson Education, Sydney.

Kaplan, L., 2004, 'Skills development in tourism: South Africa's tourism-led development strategy', GeoJournal, 60: 217-227.

Kepe, T., Ntsebeza L., and Pithers. L., 2001, 'Agri-tourism spatial development initiatives in South Africa: are they enhancing rural livelihoods?', Natural Resource Perspectives, 65:1-4, PLAAS (programme for Land and Agrarian Studies), University of the Western Cap and Overseas Development Institute, London.

Laverack, G. and Thangphet, S., 2009, 'Building community capacity for locally managed ecotourism in Northern Thailand', Community Development Journal, 44(2), 172-185.

Malatji, M. I. and Mtapuri, O., 2012, 'Can Community-Based Tourism Enterprises Alleviate Poverty? Toward a New Organization', Tourism Review International, 16, 1-14.

Manyara, G. and Jones, E., 2007, Community-based tourism enterprises development in Kenya: an exploration of their potential as avenues of poverty reduction', Journal of Sustainable Tourism, 15(6), 628-644.

Mcetywa, S. A. M., 1998, Mpondo Heritage: An Expression of Ubuntu, University of Natal: Institute of Black Research/Madiba Publishers, Durban.

Mitchell, J. and Ashley, C., 2010, Tourism and poverty reduction. Pathways to prosperity, Earthscan, London.

Mitchell, J., and Muckosy, P., 2008, 'A misguided quest: Community-based tourism in Latin America', Oversea Development Institute, Opinion, 102.

Moscardo G., 2008, Building community capacity for tourism development, CAB International, Wallingford.

Moscardo, G., 2008, 'Building community capacity for tourism development: conclusion', in G. Moscardo (Ed.), Building community capacity for tourism development, pp. 172-179, CAB International, Wallingford.

Mtapuri, O. and Giampiccoli, A., 2013. 'Interrogating the role of the state and nonstate actors in community-based tourism ventures: toward a model for spreading the benefits to the wider community', South African Geographical Journal, 95(1):1-15.

MTR - Mid Term Review, 2003 'Support to the Wild Coast Spatial development Initiative Pilot programme. Mid-term Review report project SA/99/73200/019', ECODES Consortium, Bruxelles.

Ndlovu, N. and Rogerson, C.M., 2003, 'Rural local economic development through community-based tourism: the Mehloding hiking and horse trail, Eastern Cape, South Africa, Africa Insight, 33: 124-129.

Ndlovu, N. and Rogerson, C.M., 2004, 'The local economic impacts of rural community-based tourism in Eastern Cape', in C. M. Rogerson and G. Visser (Eds.), Tourism and development issues in contemporary South Africa, pp. 436-451, Africa Institute of South Africa, Pretoria.

Ntshona, Z. and Lahiff, E., 2003, 'Community-Based Eco-Tourism on The Wild Coast, South Africa: The Case of the Amadiba Trail', SLSA Research Paper 7, Institute of Development Studies, Brighton.

Nyaupane G. P., Morais D. B. and Dowler, L., 2006, 'The role of community involvement and number/type of visitors on tourism impacts: A controlled comparison of Annapurna, Nepal and Northwest Yunnan, China', Tourism Management, 27:1373-1385.

Peredo, A. M. and Chrisman, J. J., 2006, 'Toward a theory of community-based enterprise', Academy of Management Review, 31(2):309-328.

Pereira, E. M. and Mykletun, R. J., 2012, 'Guides as Contributors to Sustainable Tourism? A Case Study from the Amazon', Scandinavian Journal of Hospitality and Tourism, 12(1), 74-94.

Pleumaron, A., 2002, 'Community-Based Ecotourism: Miracle or Menace?', Paper presented to the IYE Regional Conference on Community-Based Ecotourism in Southeast Asia, Chiang Mai/Thailand, 3-7 March 2002.

Ross, S. and Wall, G., 1999, 'Ecotourism: towards congruence between theory and practice', Tourism Management, 20:123-132.

Russell, E. and Kuiper, S., 2003, 'The Amadiba Community Tourism and Natural resource management project', in M. Hauck and M. Sowman (Eds.), Waves of Change, pp. 147-174, University of Cape Town Press, Cape Town.

Sammy, J., 2008, 'Examples of effective techniques for enhancing community understanding of tourism', in G. Moscardo (ed.), Building community capacity for tourism development, pp. 75-85, CAB International, Wallingford.

Scheyvens, R. and Russell, M., 2012, 'Tourism and poverty alleviation in Fiji: comparing the impacts of small- and large-scale tourism enterprises', Journal of Sustainable Tourism, 20(3), 417-436.

Scheyvens, R., 1999, 'The potential for ecotourism to facilitate the empowerment of local communities in Southern Africa. A summary report using selected case studies', Institute of Natural Resources, Pietermaritzburg.

Simukonda, N. and Kraai, M., 2009, 'The Wild Coast: the Contested Territory', in S. Guyot and J. Dellier (Eds.), Rethinking the Wild Coast, South Africa Eco-frontiers vs livelihoods in Pondoland, pp. 117-128, VDM Verlag Dr. Müller Aktiengesellschaft and Co. KG, Saarbrücken.

SNV - Netherlands Development Organisation, 2007, 'A Toolkit for Monitoring and Managing Community-based Tourism', SNV and University of Hawaii.

Suansri, P., 2003, Community Based Tourism Handbook, Responsible Ecological Social Tour (REST), Bangkok.

Suryia K., 2010. Impact of Community-based Tourism in a Village Economy in Thailand: An analysis with VCGE model. Paper presented at EcoMod2010 Conference. July 7, 2010 - July 10, 2010. Istanbul.

Telfer, D. J., 2009, 'Development studies and tourism', in T. Jamal and M. Robison (Eds.), The SAGE handbook of tourism studies, pp.146-165, SAGE Publications, London. 
Timothy, D., 2002, 'Tourism and community development issues', in R. Sharpley and D. J. Telfer (eds.), Tourism and Development Concepts and Issues, pp. 135-178, Channel View Publications, Clevedon.

Victurine, R. 2000. 'Building Tourism Excellence at the Community Level: Capacity Building for Community-Based Entrepreneurs in Uganda', Journal of Travel Research 2000(38): 221-229.

Weiler, B. and Ham, S. H., 2002, 'Tour Guide Training: A Model for Sustainable Capacity Building in Developing Countries', Journal of Sustainable Tourism, 10(1), 52-69.

Wright, B. B., 2005 'A review of lessons learned to inform Capacity-building for sustainable nature based Tourism development in the European Union funded "support to the wild coast Spatial development initiative pilot Programme"', Masters of Education (Environmental Education), Rhodes University.

Zapata, M.J., Hall, C.M., Lindo, P., and Vanderschaeghen, M., 2011, 'Can Community-based tourism contribute to development and poverty alleviation?', Current Issues in Tourism, 14(8), 725-749. 